Психология. Журнал Высшей школы экономики,

2021. T. 18. № 1. C. 167-181. DOI: 10.17323/1813-8918-2021-1-167-181

\title{
ЯВЛЯЕТСЯ ЛИ РЕАЛИЗАЦИЯ СИСТЕМНО-ИНФОРМАЦИОННОГО ПОДХОДА В.М. ПЕТРОВА СПОСОБОМ ПРЕОДОЛЕНИЯ КРИЗИСА В ПСИХОЛОГИИ И ДРУГИХ ГУМАНИТАРНЫХ НАУКАХ?
}

\begin{abstract}
В.М. РОЗИН
${ }^{a}$ Федеральное государственное бюджетное учреждение науки Институт философии Российской академии наук, 109240, Россия, Москва, ул. Гончарная, д. 12, стр. 1

\section{Резюме}

Автор анализирует статью В.М. Петрова, опубликованную в журнале «Мир психологии», в которой на основе системно-информационного подхода предложена перестройка гуманитарных наук. Автор сравнивает это предложение с близкой по идеям программой Л.С. Выготского 1927 г., изложенной в работе «Исторический смысл психологического кризиса. Методологическое исследование». Автор старается показать, что системный подход нужно понимать иначе, чем это делает Петров, а именно не как предельную онтологию, а как превращенную форму методологии. Кроме того, с опорой на системные разработки Г.П. Щедровицкого, а также реконструкцию истории естественных наук предлагается гипотеза, согласно которой реализация системного подхода предполагает построение двух скоординированных между собой языков - «системно-структурного» и «предметносистемного». Для Щедровицкого второй язык - это язык теории деятельности, где деятельность истолкована как система, для Петрова, вероятно, - теория информации. Автор иначе, чем Петров, представляет главные задачи реформирования психологии: это необходимость конвергенции естественно-научного и гуманитарного подходов, переосмысление связи психологической науки и практики, а также самой психологической науки, осмысление нового статуса и природы человека, попавшего в процессы перехода и сложную реальность постмодерна (посткультуры). Обсуждаются условия, необходимые для решения этих задач. В их число входит авторская концепция науки, учет двух этапов развития психологии и особенностей психологической науки, некоторых характеристик современного состояния культуры. Автор приходит к выводу, что системный подход помогает в изучении психики в рамках отдельной науки (концепции), но не реагирует на различие парадигм, кроме того, разнообразие типов человека и личности осмысляется в психологическом знании и науке в форме множества психологических концепций, теорий и практик, что совершенно нормально и вовсе не требует реформирования. Но методологическая культура психологов нуждается в совершенствовании.
\end{abstract}

Ключевые слова: система, системный подход, предмет, дисциплина, наука, схемы, идеальные объекты, концепция, реконструкция, практика.

Исследование проведено при финансовой поддержке гранта Министерства науки и высшего образования РФ («Новейшие тенденции развития наук о человеке и обществе в контексте процесса цифровизации и новых социальных проблем и угроз: междисциплинарный подход», проект № 075-15-2020-798). 


\section{Возвращение к обсуждению кризиса в психологии и гуманитарных науках}

В качестве преамбулы я бы сформулировал цель данной статьи и разговора как постановку некоторых проблем, касающихся дальнейшего развития психологии. Делаю это, обсуждая интересную работу В.М. Петрова, который склоняет читателя к научной полемике, что в настоящее время встречается нечасто.

В журнале «Мир психологии» опубликована статья В.М. Петрова «Предстоящая “перезагрузка” гуманитарных наук: вызов времени» (Петров, 2019). Он пишет не о преодолении кризиса, а о «перезагрузке» гуманитарных наук как актуальном вызове времени, но, по сути, это та же самая проблема, которую еще в 1920-е гг. обсуждал Л.С. Выготский в своей интересной работе «Исторический смысл психологического кризиса (методологическое исследование)». Если у Выготского единицами анализа ситуации в психологии выступают понятия «идея», «дисциплина», «наука», «система наук», то у Петрова - это «парадигмы». На мой взгляд, большой разницы нет, просто Выготский по понятным причинам еще не читал «Структуру научных революций» Томаса Куна. Вызов времени оба автора видят примерно в одном множестве несовпадающих представлений об изучаемой реальности (психике и других объектах гуманитарной науки), отсутствии единой системь науки, отставании методологии науки. И ответ на этот вызов очень близкий - вместо множества противоречивых представлений (дисциплин, наук) нужно построить единую науку, основанную на строгой иерархической организации и центральном правильном понятии, схватывающем пусть и на достаточно абстрактном уровне, но все же сущность изучаемого явления. Сравним.

«Современная научная психология переживает глубочайший кризис своих методологических основ <..> ...отсутствие общепризнанной системы науки. Каждое изложение психологии у виднейших авторов построено по совершенно иной системе. Все основные понятия и категории толкуются по-разному... $<. .>$ Единство отдельных психологических предметов и дисциплин в «общей психологии», которую предстоит построить, достигается путем подчинения, господства, путем отказа отдельных дисциплин от суверенитета в пользу общей науки. Внутри нового целого образуется не сосуществование отдельных дисциплин, но их иерархическая система, имеющая главный и вторичный центры, как Солнечная система... <... . ..даже самому отвлеченному, последнему понятию соответствует какая-то черта действительности» (Выготский, 1982, с. $300,312,370,373)$.

«...Имеются конкретные знания о множестве частных фактов (например, относящихся к сфере творчества), известно небольшое количество более или менее достоверных закономерностей (скажем, относящихся к психофизике), но практически нет единой принятой научным сообществом целостной концепчии ментальной жизни человека... <..> Стало быть, если поставить в качестве первого (самого предварительного) ориентира исследования выбор оптимальной парадигмь, то следует сосредоточиться на ее возможньх очертаниях... 
<..> Словом, единую модель гуманитарной сферь, включающую ее ядро ментальные процессы, еще только предстоит построить! И именно в этом заключается ВЫЗОВ ВРЕМЕНИ: без такой модели мы обречены на бесплодное блуждание в мире частностей < ..> нас может ждать весьма печальная перспектива - при отсутствии единой системной иерархически организованной модели гуманитарного знания <...> следует ориентироваться на парадигмы максимально общего характера... В такой “раскладке” главная, центральная парадигма обеспечивает принципиальную правильность (либо, наоборот, неправильность) “общего хода” всех рассуждений, тогда как некие частные парадигмы дают решения для множества конкретных моделей - ситуаций, складывающихся в каждой области <...> Только тогда есть надежда прибегнуть к помощи вышеописанного феномена централизащии - связать друг с другом разных “абонентов” через некую надстроенную над ними всеми “обобщающуюю” (“центральную”) парадигму...» (Петров, 2019, с. 223, 226, 227-228). Почти через сто лет В.М. Петров воспроизводит структуру мысли Л.С. Выготского. Выготский видел решение поставленных им проблем на путях реализации в психологии естественно-научного подхода (хотя сам скорее действовал как гуманитарий). Точнее, что видно по многим его работам: он сидел на двух, если не на трех, стульях. Например, в книге «Язык и мышление» Выготский, с одной стороны, заявляет, что он будет вести исследования, ориентируясь на методы Френсиса Бэкона, с другой стороны, анализирует мышление подобно гуманитарию, в духе В. Дильтея, с третьей стороны, пытается представить развитие мышления, беря в образец генезис в «Капитале» Маркса.

В. Петров считает, что будущее скорее за системным (системно-информационным) подходом. «Дело в том, - пишет он, - что именно этот подход инвариантен относительно конкретной области “материальной природы” любых научных областей (и поэтому позволяет интегрировать их совокупность в единую системную целостность...)» (Там же, с. 220).

\section{Онтологический и методологический аспекты системного подхода}

Вероятно, Петров не знает или не хочет знать, что в целом психология не пошла за Выготским (исключение - теория деятельности А.Н. Леонтьева и его последователей): общую психологию никто не построил, а количество психологических наук, по-разному истолковывающих психику, в сравнении со временем написания работы Выготского возросло на порядок, если не больше. Как известно, не оправдались и ожидания сторонников системного подхода, утверждавших в 1960-1970-е гг., что системный подход заменит собой методологию и философию и станет универсальным языком науки. Но этот аргумент очень общий, необходим анализ конкретной ситуации, которую обсуждает Петров (Бог, как известно, в деталях). Поэтому обсудим. Начну с проблемы демаркации системного подхода и методологии.

Обратите внимание на фразу Петрова «центральная парадигма обеспечивает принципиальную правильность (либо, наоборот, неправильность) “общего хода” всех рассуждений», т.е. получается, что системный подход - это 
методология, т.е. предписания, обеспечивающие правильность мышления. Но обычно системный подход понимается иначе, скорее как «предельная онтология»: система хотя и не объект, но что-то вроде него - особая онтология, в рамках которой можно правильно помыслить (и конструировать) любой сложный объект (например, психику), правильно его анализировать и синтезировать. А методология вроде бы отличается от онтологии; скажем, по Г.П. Щедровицкому, это знания и проекты мышления и деятельности. «Итак, методолог, - пишет Щедровицкий, - (в отличие от ученого) - это человек, который работает над собственной деятельностью и собственным мышлением, меняя их, трансформируя, создавая новые формы - сначала в мысли, а потом в реализации» (На досках, 2004, с. 131, 184-185). Создание новых видов деятельности и мышления Щедровицкий мыслит проектно и нормативно, «и этим же, - пишет он, - определяется основная функция методологии: она обслуживает весь универсум человеческой деятельности прежде всего проектами и предписаниями» (Там же, с. 95).

Если принять подобное противопоставление, то спрашивается: системный подход - это онтология или методология? Думаю, это особый, странный вариант методологии, когда процедуры мысли и деятельности не заданы явно, именно как процедуры, а указаны, так сказать, латентно, посредством онтологии (кстати, примерно так же устроены философские категории). Ведь что такое система? В качестве образа, схемы - это определенное построение, и в этом смысле объект (целое, подсистемы, элементы, связи и отношения, иерархическая организация и пр.). Но посредством этих схем и образов задаются процедуры правильного системного мышления: определяем, нащупываем целое, противопоставляем его среде или другим целым; мыслим части и подсистемы как обусловленные этим целым, а целое - как составленное из этих частей; определяем единицы (элементы, подсистемы) как самостоятельные образования и одновременно как зависимые от других единиц и пр. и пр.

Системный подход - это, так сказать, «превращенная форма методологии», методология в форме онтологии. В этом его преимущество, но и недостаток. Кстати, первоначально в философии античной культуры и Средних веков методология чаще всего существовала именно в форме онтологии, только в Новое время, когда в центр философской мысли было поставлено мышление (Ф. Бэкон, Р. Декарт, И. Кант) и сформировалась специфическая рефлексия деятельности, в начале XX столетия методология была выделена сначала как самостоятельный жанр (Л.С. Выготский, С. Франк), затем философская дисциплина.

Как онтология система воспринимается предметником (ученым или философом) в виде обобщенной модели изучаемого явления («следует, - замечает Карпов, - ориентироваться на парадигмы максимально общего характера»). Но поскольку процедуры здесь заданы неявно, их, во-первых, можно толковать субъективно, что и происходит в практике исследования и конструирования сложных явлений, во-вторых, многие реальные процедуры не укладываются в образ и схемы системы, ведь системный подход - это хотя и важный, но только один вариант методологии. Именно такой, где исследователю или 
инженеру приходится иметь дело с «многими знаниями и предметами», которые только в совокупности должны задавать сложное явление, поэтому приходится решать задачи синтеза и анализа, определения целого и частей, действия по логике обусловленности и зависимости и пр. Но существуют и другие стратегии «мыследействия», не требующие системного подхода, они поддерживаются другими подходами, например, феноменологическим, семиотическим, гуманитарным, культурно-историческим. Скажем, в феноменологии тоже осуществляется синтез разных знаний, но иначе, за счет тематизации и схватывания («концепирования») разных представлений в сознании мыслящего.

\section{Системный подход как способ преодоления сложности}

Моделесообразность системного подхода часто подводит исследователя, ему кажется, что можно упростить сложный синтез и анализ предметов и знаний, как правило, предполагающие методологическую рефлексию, заменив их системным анализом и синтезом. Пример подобного хода мысли находим у моего учителя Г.П. Щедровицкого (1993, 1995а). Столкнувшись в ходе педагогического исследования человека с ситуацией многих знаний и предметов (эта ситуация создается самим исследованием, заставляющим выделять в ходе анализа и частично обособлять различные стороны и составляющие изучаемого явления), Г.П. Щедровицкий решил облегчить себе задачу, обратившись к системному подходу. «Педагогика требует такого научного знания о человеке, которое бы объединяло все три описанных выше представления о человеке (как личности, социального индивида и биологического существа. B.P.), синтезировало бы их в одном многостороннем и конкретном теоретическом знании... Но сегодня теоретическое движение не может ее разрешить, ибо нет необходимых для этого средств и методов анализа. Задачу приходится решать сначала на методологическом уровне, вырабатывая средства для последующего теоретического движения, в частности на уровне методологии системно-структурного исследования» (Щедровицкий, 1995а, с. 370). «Поэтому мы должны попытаться каким-то образом свести все эти моменты к более простым отношениям и механизмам, чтобы затем вывести их из последних и таким образом организовать все в единую систему» (Щедровицкий, 1995b, с. 273).

Системный подход, утверждает Щедровицкий, определяет методы изучения как деятельности вообще, так и любых конкретных видов деятельности. Анализ работы «Человек как предмет исследования» и ряда других показывает, что принципы системного подхода и системные представления для Щедровицкого в этот период заменяют логику. «Каждая из этих схем (речь идет о схемах, по которым строятся в науке модели «человека». - B.P.) требует для своего развертывания особого методического аппарата системно-структурного анализа. Различие между ними распространяется буквально на все на принципы анализа и обработки эмпирических данных. На порядок рассмотрения частей моделей и относящихся к ним свойств, на схемы конструирования разных “сущностей”, превращающих эти схемы в идеальные объекты, 
на схемы связи и объединения свойств, относящихся к разным слоям описания объекта» (Щедровицкий, 1995а, с. 376). Другая функция системно-структурного анализа в работах Щедровицкого - обеспечивать синтез и конфигурирование разных предметов знания, разных объектных представлений, что тоже можно отнести к ведению логики, правда, понимаемой широко. Дело в том, что Щедровицкий еще в начале своего творчества противопоставил две логики - формальную, которую он критиковал за принцип «параллелизма формы и содержания», и «содержательно-генетическую» (именно ее Щедровицкий со своими коллегами развивает и трактует достаточно широко, отчасти в духе методологии).

В основном с этими положениями можно согласиться, за исключением широкого обобщения: не все явления можно рассмотреть как деятельность, кроме системного подхода, существуют другие (феноменологический, семиотический, психоаналитический, когнитивный, биологический, информационный и др.).

\section{Системно-структурный и предметно-системный языки описания изучаемой реальности}

Стоит отметить, что вариант построения Г.П. Щедровицким системного подхода отличался от существовавших в тот период (А. Богданова, Л. Берталанфи, Т. Парсонса, А. Уемова, В. Садовского). Дело в том, что предметом методологического изучения и конструирования для Щедровицкого выступала деятельность. Правда, трактовка им деятельности серьезно отличалась от психологической, он понимал деятельность не как активность и процесс субъекта (индивида), а как деиндивидуальную структуру, для которой характерны не только «акт деятельности» (здесь можно увидеть совпадение с психологической традицией), но и воспроизводство, разделение и кооперация труда, процессы трансляции и коммуникации.

Щедровицкий знал, что существуют различные варианты системного подхода, в частности, предполагал, что системный подход может противоречить деятельностному подходу в том виде, как он задавался в методологии. В результате Щедровицкий выходит на следующее решение - системный подход нужно построить заново в рамках самой методологии.

«Главная идея нашего предложения состоит в том, чтобы объединить разработку системного подхода с разработкой новых приемов и способов мышления, которые мы называем “методологическими”... специфика системного подхода может быть определена только при описании структуры и форм организации методологической работы, ибо, по нашему убеждению, системный подход существует только как подразделение и особая организованность методологии и методологического подхода» (Щедровицкий, 1995б, с. 94, 101-102). Отсюда вытекало, что, если системный подход должен быть построен в рамках методологии, его нужно спроектировать, исходя из методологических задач. Одновременно предполагалось, что сами методологические построения нужно проработать с точки зрения заново выстроенных системно-структурных категорий. 
Поскольку предмет методологии мыслился как деятельность, ее необходимо было представить в рамках системного подхода, что и было сделано. «Исходное фундаментальное представление: деятельность - система», пишет Щедровицкий в работе 1975 г. (Щедровицкий, 1995в, с. 241).

Если обобщить эту программу построения системного подхода, то можно сформулировать следующую гипотезу. Реализация системного подхода предполагает построения сразу двух скоординированных между собой языков «системно-структурного» $и$ «nредметно-системного». Для Г.П. Щедровицкого второй язык - это язык теории деятельности, где деятельность истолкована как система. Для В.М. Петрова, вероятно, теория информации. Психология для обоих авторов не является основным предметом осмысления, они ее рассматривают как одну из научных дисциплин в рамках предлагаемых онтологий. Необходимость построения предметно-системного языка можно пояснить, вспомнив историю формирования естествознания. Именно там впервые встала обсуждаемая нами проблема и была решена путем построения указанных двух языков. Обращение к истории науки всегда полезно, оно позволяет многое понять и в отношении психологии.

\section{Экскурс в историю естествознания: «теория широты форм» в роли предметно-системного языка}

Еще в XIII столетии Роджер Бэкон, следуя за Платоном, заявил, что языком описания природы («подлунного мира») выступает математика. В «Opus Tertium» читаем: «Вторые же важнейшие ворота, которых нам по природе недостает, есть знание математики... ясно, что она простая наука и как бы врожденная или близкая врожденному знанию. Из этого следует, что она - первейшая из наук, без которой другие не могут познаваться... Адам и его сыновья получили ее от Бога... понятно, что бо́льшая и лучшая часть математики повествует о вещах небесных, как астрология, спекулятивная и практическая... благодаря этим [двум наукам о небесном] подготавливается тем не менее познание этого подлунного мира... познание всего подлунного зависит от возможностей математики» (Бэкон, 2002, с. 103-109).

Однако понятия поздней эллинистической античной математики (теории пропорций и геометрии) существенно отличались от построенных Аристотелем физических понятий, с помощью которых описывались природные явления. Чтобы реализовать замысел математизации науки о природе, в Средние века создается промежуточный язык - особая дисциплина, получившая название «учение о широте форм», или «интенсификация и ремиссия качеств», без которой не состоялась бы естественная наука Нового времени. Эта дисциплина, пишут А.Т. Григорьян и В.П. Зубов, «столь не похожая по своему облику на позднейшую кинематику, сколь не похожи друг на друга человеческий зародыш и сформировавшийся человек», ставила своей целью «математизировать учение об интенсивности качеств и его изменении, то ли предпочтительно в арифметико-алгебраической форме, как делали это в первой половине XIV в. ученые Мертон-колледжа в Оксфорде, то ли в форме 
геометрической, как это делали Николай Орем и его последователи, то ли, наконец, сочетая оба пути, как это делали итальянцы в XV-XVI вв.» (Григорьян, Зубов, 1962, с. 122).

Понятия «учения широты форм», с одной стороны, опирались на философские категории «отношение», «форма», «качество», «количество», с другой - могли быть рассмотрены как схемы, позволяющие описывать природные явления, чем позднее и воспользовался Галилей, создавая свое знаменитое учение о свободном падении тел. Как показывают Григорьян и Зубов, Галилей читал «учение о широте форм», в частности, использовал в своем творчестве основную работу Орема («Трактат о конфигурации качеств»), из которой он заимствовал, во-первых, закон свободного падения тел («треугольник Орема»), во-вторых, идею и геометрический метод доказательства теоремы об эквивалентности движений, в-третьих, терминологию и ряд основных понятий (Там же, с. 133, 144, 145).

Предметно-структурный язык, о котором мы говорили выше, выполняет примерно такую же роль, как «теория широты форм», выступившая посредником между математикой и физическими понятиями, он позволил реализовать системный подход применительно к конкретным предметам (дисциплинам). Анализ этого кейса позволяет утверждать, что нет одного универсального и одинакового для всех предметов и дисциплин системного подхода. Напротив, для отдельной области предметов создается свой вариант такого подхода, включающий два языка - системно-структурный и предметносистемный. Говоря о «системно-информационном» подходе, Петров фактически признает наличие таких двух языков. Но в связи с этим можно задать и более общий вопрос: в каком системном подходе нуждается психология?

\section{«Перезагрузка психологии» или решение актуальных методологических проблем психологии?}

Мне трудно, однако, согласиться с тем, какую главную задачу видит Петров в гуманитарных науках, говоря о необходимости их «перезагрузки». Если иметь в виду психологию, то подобную задачу, по Петрову, можно было бы сформулировать так: главная проблема, каким образом преодолеть множество разных представлений психики, построив единую науку, единую модель, выйдя на целостную концепцию ментальной жизни человека.

Но так можно было бы рассуждать, предполагая, что существует один тип человека (точка зрения, характерная для Древнего мира и Средних веков). В культуре Нового времени («модерна») мыслить подобным образом уже невозможно. Культура модерна допускает не только разные каналы и способы социализации, но и разные типы человека, тем более разные типы личности. Мало того, именно психология вместе с современной философией разработали разные концепции (схемы) для разных типов людей модерна.

Например, человек «по Фрейду» и «по Роджерсу» - это не два варианта одной и той же психической структуры, а два разных типа личности и человека. Первый мыслится, во-первых, как конфликтное существо (конфликт личности 
и культуры, сознания и бессознательного, психоаналитика и клиента, отсюда феномен сопротивления), во-вторых, как этически слабая личность, разрешающая себе многое (поскольку бессознательное сильнее сознания), в-третьих, психоанализ предполагает и особый тип коммуникации (психолог знает, как устроен его клиент, и незаметно вменяет, навязывает ему это знание, даже против его воли). Человек по Роджерсу, напротив, ориентирован на эмпатию и сотрудничество, на доверительную коммуникацию, не склонен отдаваться бессознательным влечениям, стремится перебарывать свои слабости. В культуре модерна мы, естественно, найдем соответствующие этим двум антропологическим типам каналы социализации и общения.

Таким образом, с моей точки зрения, построение единой психологии не только не является главной задачей, но, напротив, создало бы в психологии дополнительные проблемы. Центральные проблемы в психологии другие: необходимость конвергенции естественно-научного и гуманитарного подходов, переосмысление связи психологической науки и практики, а также самой психологической науки, осмысление нового статуса и природы человека, попавшего в процессы перехода и сложную реальность постмодерна (посткультуры). Например, как показывает Ф.Е. Василюк, обособление психологической науки и практики стало уже совершенно недопустимым, грозя самой системе психологического знания. Не менее удручающе выглядит распадение психологии на два типа - естественно-научной психологии и гуманитарной. Ну, а проблемы жизни и существования человека в переходной период у всех на слуху. В данном случае я только указываю на эти проблемы, постановка и направление их решения рассмотрены подробно в нескольких моих книгах и статьях.

Другой вывод, следующий из рассмотренного материала, такой: системный подход помогает в изучении психики в рамках отдельной науки (концепции, дисциплины), но не реагирует на различие парадигм. И психоаналитик, и сторонник концепции Роджерса могут использовать понятия системы и системные методы, но это не сближает и не связывает эти концепции, они продолжают оставаться разными в парадигмальном отношении. Задачи синтеза и конфигурирования многих знаний и предметов, а также мышления с учетом целого одинаково актуальны для любой сложной парадигмы.

В споре физиков и гуманитариев Выготский решительно встал на позицию первых. «Существуют две психологии,- писал он,- естественно-научная, материалистическая, и спиритуалистическая: этот тезис вернее выражает смысл кризиса, чем тезис о существовании многих психологий; именно психологий существует две, т.е. два разных, непримиримых типа науки, две принципиально разные конструкции системы знания <...> Психотехника поэтому не может колебаться в выборе той психологии, которая ей нужна (даже если ее разрабатывают последовательные идеалисты), она имеет дело исключительно с каузальной, с психологией объективной; некаузальная психология не играет никакой роли для психотехники... эта психология, кроме того, есть наука эмпирическая, сравнительная, наука, пользующаяся данными физиологии, и, наконец, экспериментальная наука» (Выготский, 1982, с. 387, 390). 
На мой взгляд, в психологии нельзя отказаться ни от естественно-научного, ни от гуманитарного подходов, но они реализуются лишь частично и в связи друг с другом (Розин, 2018, с. 130-131). С одной стороны, Выготский правильно отмечал, что именно личность представляет главный интерес для психологии, но с другой - существуют общие условия жизни (например, все люди в своем развитии проходят культуру детства, культуру подросткового возраста и юношества, культуру взрослого человека, культуру пожилого возраста и старости; и все мы живем в условиях завершающегося модерна и становления посткультуры).

Так вот, для психологического осмысления разных типов человека модерна и разных типов личности (массовой, уникальной, девиантной, социальной и асоциальной, эгоистической и пр.) необходим гуманитарный (социогуманитарный) подход, а для осмысления характеристик психики, формирующихся в общих условиях,- естественно-научный, точнее, его гибридный вариант, ведь человек все же только частично принадлежит первой природе, он в значительной степени семиотическое, деятельностное, рефлексивное и духовное существо.

\section{Авторская концепция науки}

В свою очередь, для подобного осмысления нужно решить проблему конвергенции этих подходов и построить новую концепцию науки. Эта концепция должна включать в себя на равных правах разные типы наук-естественные, гуманитарные, сощиальные, возможно, «технонауку» и новый тип науки, назовем ее «комплексной» (для комплексной науки характерны современные «междисциплинарные» и «трансдисциплинарные» исследования) (Розин, 2012). В последнем варианте подобной концепции я различил два плана науки. Первый был получен в ходе генезиса науки (я его назвал «геном науки»), второй - анализа особенностей современной науки (соответственно «наука как институт модерна»). Вот характеристики генома науки.

Наука представляет собой ращиональную форму познания действительности. Познание осуществляется путем построения идеальных объектов. Идеальным объектам философ или ученый приписывает такие свойства, которые позволяют в рамках рассуждений или доказательств получить непротиворечивые знания, решить стоящие перед исследователем проблемы и задачи, описать и осмыслить эмпирические проявления изучаемого явления. Наука предполагает концептуализацию, т.е. построение концепций науки, представляющих собой осмысление и описание науки в философии или методологии. Именно в контексте концептуализации науки вырабатываются такие понятия, как наука, теория, истина, знание, доказательство, строгость, объективность и др.

Теперь обозначим характеристики науки как института модерна. Научные знания, схемы и законы понимаются как репрезентирующие объективно существуюшую реальность. Они ориентированы на использование в определенных практиках (инженерной, педагогической, реабилитации, политики и др.). 
Миссия науки состоит, с одной стороны, в указанном объективном описании действительности, с другой - в получении знаний, позволяющих овладеть природными процессами (рассчитывать их, управлять ими).

При этом природа понимается не однозначно: это и первая природа, законы которой изучаются в естествознании, и социальная природа, и природа психики и т.д. Для функционирования и развития науки необходимы подготовленные спещиалисты, а также немалье средства (финансовые и материальные).

Способы получения в науке знаний, соответственно, схем, закономерностей, законов, теорий и т.д., а также большинство других процедур, составляющих функционирование науки, как правило, нормированы. Наука как институт предполагает организацию и управление, а также самоорганизацию и активность научного сообщества. Наука живет не в пустом пространстве, а взаимодействуя с другими институтами (власти, образования, промышленности и др.) и обществом. В науке как институте модерна разрабатываются концепции науки. В Новое время геном науки адаптировался к требованиям институтов модерна. Например, научные исследования (построение идеальных объектов и знаний) ориентированы на практические приложения, возросла роль методологического сопровождения, позволяющая оценивать научные исследования на объективность и эффективность.

Можно показать, что предложенная здесь концепция позволяет решить проблему конвергенции естественно-научного и гуманитарного подходов. Во-первых, оба подхода удовлетворяют требованиям генома науки: в них осуществляется познание (в первом явлений и процессов природы, во втором произведений и стоящих за ними явлений - личности, культуры, истории и пр.), решаются проблемы, строятся идеальные объекты и опирающиеся на них теоретические знания, имеет место осознание (концептуализация). По содержанию указанные здесь характеристики естественной науки отличаются от характеристик гуманитарной науки (Розин, 2018).

Во-вторых, естественные и гуманитарные науки удовлетворяют нормам науки как института модерна. В них описывается объективно существующая реальность, имеет место ориентация на практические приложения, разрабатываются требования к научному познанию и концепции науки, подготавливаются специалисты (ученые), оба типа науки поддерживаются и финансируются государством.

Психология, конечно, наука, но наука особая, ориентированная на психологические практики и указанное выше разнообразие типов человека и личности. В этом отношении важно понять, каким образом создаются и используются ее идеальные объекты. Как я показываю, идеальные объекты создаются с опорой на схемы, т.е. первоначально строятся схемы (яркий пример в психологии - схемы 3. Фрейда), позволяющие разрешить проблемы и вызовы времени; схемы задают новую реальность и позволяют по-новому действовать (таблица 1) (Розин, 2017, с. 21, 29, 39).

Затем на основе схем строятся идеальные объекты. Существуют два варианта (пути) дальнейшего развития - теоретический, когда с опорой на одни 
Таблица 1

Методологическая схема

\begin{tabular}{|c|c|c|}
\hline $\begin{array}{c}\text { Проблемная } \\
\text { ситуация }\end{array}$ & $\begin{array}{c}\text { СХЕМА } \\
\text { семиотический предмет }\end{array}$ & $\begin{array}{c}\text { новая деятельность } \\
\text { новая реальность }\end{array}$ \\
\hline первая фаза & вторая фаза & третья фаза \\
\hline
\end{tabular}

идеальные объекты создаются другие и таким образом выстраивается теория (что предполагает рефлексию и формирование доказательств), и прикладной, в рамках которого идеальные объекты используются для построения новых схем, необходимых для решения практических задач.

Психология в своем развитии прошла два этапа. На первом преимущественно реализовался первый вариант, т.е. психология мыслилась и строилась как теория (наука). На втором этапе перевес получил второй вариант: здесь идеальные объекты создавались, не столько исходя из чисто познавательного отношения (как там на самом деле устроена психика), а для решения практических задач (помощи личности в ее развитии, задач реабилитации, восстановлении психического здоровья, совершенствовании эффективности поведения, деятельности и пр.). При этом, безусловно, психологические теории помогали строить новые схемы для психологических практик, но не стоит забывать, что за теориями стояли определенные проблемы и вызовы времени, для которых были характерны прагматически-ценностные отношения.

Кризис современной психологической науки, на мой взгляд, во многом связан с трактовкой науки по образцу естествознания, а также с непониманием того, что идеальные объекты психологических теорий создаются на основе схем, которые используются двояко - для построения самой теории и решения прикладных задач. Разнообразие типов человека и личности осмысляется в психологическом знании и науке в форме множества психологических концепций, теорий и практик, что совершенно нормально и не вовсе требует реформирования («перезагрузки»). Другое дело методологическая культура (например, различение схем и идеальных объектов, теории и ее онтологии, критериев истинности и эффективности знаний и др.), она оставляет желать лучшего. Конечно, психологи за редким исключением не могут совмещать собственно психологическую и методологическую компетенции, как это, например, было характерно для Федора Василюка или в настоящее время для Андрея Пузырея, но сейчас методологическая грамотность совершенно необходима в любой науке и практике, тем более антропологически ориентированной.

Достаточно очевидно, что разные типы личности и человека обусловлены характером сложившейся культуры и социального порядка (социальными институтами и социальными нормами), а также состоянием общества. Но в настоящее время все это пришло в движение, претерпевает трансформацию. Как уже отмечалось, завершается культура модерна, налицо становление посткультуры. 
С одной стороны, перестают удовлетворительно работать социальные институты, не исключая государства, и ослабевает, распадается общество, с другой - формируются новые типы социальности - метакультуры (Общий рынок, Китай и США с зонами экономического и культурного влияния и т.д.), на основе Интернета и мобильной связи складываются сетевые сообщества, происходит конвергенция социалистических и капиталистических форм хозяйствования и управления, бурно развиваются новые технологии, в том числе такие, которые позволяют использовать социальные институты не по назначению.

Как одно из следствий этих процессов (мы указали только некоторые), под их влиянием начинают трансформироваться и сложившиеся типы личности и человека. Возрастает маргинальность, девиантное поведение, все чаще в одном человеке сходятся психические структуры, ранее принадлежавшие отдельным типам, или, наоборот, психика деградирует к вроде бы канувшим в Лету архаическим типам. Все труднее современному человеку понять, что происходит, выработать сценарий и стратегию поведения и жизни, справляться с многочисленными проблемами. Понятно, что для психологии это означает новые вызовы, а также необходимость переосмыслить сложившиеся схемы и концепции. Не «перезагрузка» нужна психологии, она вступает в новый этап развития, где возникают новые проблемы и возможности для творчества и служения человеку.

\section{Литература}

Бэкон, Р. (2002). Opus Tertium. В кн. Антология средневековой мысли (т. 2, с. 89-122). СПб.: РХГИ. Выготский, Л. С. (1982). Исторический смысл психологического кризиса. В кн. Л. С. Выготский, Собрание сочинений (т. 1, с. 291-437). М.: Педагогика.

Григорьян, А. Т., Зубов, В. П. (1962). Очерки развития основных понятий механики. М.: Изд-во AH CCCP.

На досках. Публичные лекции по философии Г.П. Щедровицкого. (2004). М.: ШКП.

Петров, В. М. (2019). Предстоящая «перезагрузка» гуманитарных наук: вызов времени (A la recherché du noyau perdu - В поисках за утраченным локусом). Мир психологии, 3, 220-230.

Розин, В. М. (2012). Обсуждение феномена трансдисциплинарности - событие новой научной революции. Вопросы философии, 11, 85-96.

Розин, В. М. (2017). Введение в схемологию: схемы в философии, культуре, науке, проектировании. M.: URSS.

Розин, В. М. (2018). Особенности дискурса и образиъь исследования в гуманитарной науке. M.: URSS. Щедровицкий, Г. П. (1993). Система педагогических исследований. Методологический анализ. В кн. Педагогика и логика (с. 12-132). М.: Касталь. Также см.: https://gtmarket.ru/laboratory/basis/6738

Щедровицкий, Г. П. (1995, а). «Человек» как предмет исследования. В кн. Г. П. Щедровицкий, Избранные труды (с. 367-399). М.: ШКП.

Щедровицкий, Г. П. $(1995,6)$. Принципы и общая схема методологической организации системо-структурных исследований и разработок. В кн. Г. П. Щедровицкий, Избранные труды (c. 88-115). М.: ШКП. 
Щедровицкий, Г. П. (1995, в). Исходные представления и категориальные средства теории деятельности. В кн. Г. П. Щедровицкий, Избранные труды (с. 233-281). М.: ШКП.

Розин Вадим Маркович - главный научный сотрудник, ФГБУН «Институт философии РАН», доктор философских наук, профессор.

Сфера научных интересов: методология, психология, философия.

Контакты: rozinvm@gmail.com

\title{
Is the Implementation of a System-Information Approach by V.M. Petrov a Method for Overcoming Crisis in Psychology and Other Human Sciences?
}

\author{
V.M. Rozin ${ }^{\mathrm{a}}$ \\ a Institute of Philosophy, Russian Academy of Sciences, 12/1 Goncharnaya Str., Moscow, 109240, \\ Russian Federation
}

\begin{abstract}
The article analyzes the work by V.M. Petrov, published in the journal World of Psychology, in which he proposes a restructuring of the humanities based on a system-information approach. The author of the present article compares this proposal with the ideas by L.S. Vygotsky, 1927, set out in his work The Historical Meaning of the Psychological Crisis. Methodological Research). The present article tries to show that the systemic approach must be understood differently than Petrov does, namely not as the ultimate ontology, but as a transformed form of methodology. In addition, relying on systemic development of G.P. Shchedrovitsky, as well as the reconstruction of the history of the natural sciences, a hypothesis is proposed, according to which the implementation of the systemic approach involves the construction of two coordinated languages - "systemic-structural" and "objective-systemic". For Shchedrovitsky, the second language is the language of the theory of activity, where activity is interpreted as a system, while for Petrov, probably, it is the theory of information. The author has a different view from Petrov's on the main tasks of reforming psychology: there is a need for convergence of natural-scientific and humanitarian approaches, rethinking the connection between psychological science and practice, as well as reconsideration the psychological science itself, understanding the new status and nature of a person who has fallen into the transition processes and the complex reality of postmodernism (post-culture). He discusses the conditions required for solving these problems. These include the author's concept of science, accounting for the two stages of psychology development and specifics of psychological science, as well as some specifics of the current state of culture. The author comes to the conclusion that the systemic approach helps in the study of the mind within the framework of a separate science (concept), but does not respond to the difference in paradigms, in addition, the diversity of human and personality types is conceptualized in psychological knowledge and science in the form of many psychological concepts, theories and practices, which is completely normal and does not require reform. But the methodological culture of psychologists needs to be improved.
\end{abstract}


Keywords: system, systemic approach, subject, discipline, science, schemes, ideal objects, concept, reconstruction, practice.

\section{References}

Bacon, R. (2002). Opus Tertium. In Antologiya srednevekovoi mysli [Anthology of medieval thought] (Vol. 2, pp. 89-122). Saint Petersburg: RKhGI. (in Russian)

Grigor'yan, A. T., \& Zubov, V. P. (1962). Ocherki razvitiya osnovnykh ponyatii mekhaniki [Essays on the development of basic concepts of mechanics]. Moscow: Izdatel'stvo AN SSSR. (in Russian)

Na doskakh. Publichnye lektsii po filosofii G.P. Shchedrovitskogo [On the boards. Public lectures in philosophy by G. P. Shchedrovitsky]. (2004). Moscow: ShKP. (in Russian)

Petrov, V. M. (2019). Towards changing the foundations of human sciences: the challenge of time (A la recherché du noyau perdu). Mir Psikhologii, 3, 220-230. (in Russian)

Rozin, V. M. (2012). Obsuzhdenie fenomena transdistsiplinarnosti - sobytie novoi nauchnoi revolyutsii [Discussion of the phenomenon of transdisciplinarity - an event of a new scientific revolution]. Voprosy Filosofii, 11, 85-96. (in Russian)

Rozin, V. M. (2017). Vvedenie v skhemologiyu: skhemy v filosofii, kul'ture, nauke, proektirovanii [Introduction to schematics: schemas in philosophy, culture, science, design]. Moscow: URSS. (in Russian)

Rozin, V. M. (2018). Osobennosti diskursa i obraztsy issledovaniya v gumanitarnoi nauke [Specifics of discourse and the research patterns in the humanities]. Moscow: URSS.

Shchedrovitsky, G. P. (1993). Sistema pedagogicheskikh issledovanii. Metodologicheskii analiz [The system of pedagogical research. Methodological analysis]. In Pedagogika i logika [Pedagogy and logic] (pp. 12-132). Moscow: Kastal'. Retrieved from https://gtmarket.ru/laboratory/basis/6738 (in Russian)

Shchedrovitsky, G. P. (1995, a). "Chelovek" kak predmet issledovaniya ["Human" as a subject of research]. In G. P. Shchedrovitsky, Izbrannye trudy [Selected works] (pp. 367-399). Moscow: ShKP. (in Russian)

Shchedrovitsky, G. P. (1995, b). Printsipy i obshchaya skhema metodologicheskoi organizatsii sistemostrukturnykh issledovanii i razrabotok [Principles and general scheme of the methodological organization of systemic-structural research and development]. In G. P. Shchedrovitsky, Izbrannye trudy [Selected works] (pp. 88-115). Moscow: ShKP. (in Russian)

Shchedrovitsky, G. P. (1995, c). Iskhodnye predstavleniya i kategorial'nye sredstva teorii deyatel'nosti [Initial representations and categorical means of the activity theory]. In G. P. Shchedrovitsky, Izbrannye trudy [Selected works] (pp. 233-281). Moscow: ShKP. (in Russian)

Vygotsky, L. S. (1982). Istoricheskii smysl psikhologicheskogo krizisa [The historical meaning of the psychological crisis]. In L. S. Vygotsky, Sobranie sochinenii [Collected works] (Vol. 1, pp. 291437). Moscow: Pedagogika. (in Russian)

Vadim M. Rozin - Chief Research Fellow, Institute of Philosophy, Russian Academy of Sciences, DSc in Philosophy, Professor.

Research Area: methodology, psychology, philosophy.

E-mail: rozinvm@gmail.com 